\section{USE OF MSOFA FOR TRIAGE OF DISASTER PATIENTS}

\section{To the Editor:}

The study by Grissom et al ${ }^{1}$ demonstrated a high correlation of the Modified Sequential Organ Failure Assessment (MSOFA) with the Sequential Organ Failure Assessment (SOFA) to predict mortality in patients with critical illnesses. The accompanying editorial by Rubinson et $\mathrm{al}^{2}$ cautioned readers not to rely solely on the SOFA or MSOFA score to prioritize patients during a mass critical care event.

After careful consideration, the Wisconsin Hospital Preparedness Program, ${ }^{3}$ through the Medical College of Wisconsin Center for Medical Incident Management and Preparedness, ${ }^{4}$ has adapted and incorporated the SOFA score into its clinical management guidelines for hospital health care providers when routine critical care resources are not available. We welcome the work of Grissom and colleagues to simplify our model guidelines.

The Wisconsin guidelines are intended to standardize the establishment of a patient care rank order based on available resources; stated simply, triage. The Wisconsin Multiprincipled Critical Care Resource Allocation System (MCCRAS) is based on the multiprinciple allocation system proposed by White et $\mathrm{al}^{5}$ that includes doing the greatest good for the greatest number of people, maximizing life-years saved and giving individuals an equal opportunity to pass through the stages of life.

Thus, we incorporated the SOFA score as 1 of 3 variables involved in generating a MCCRAS score of 0 to 15 . This 16point scale allows for a greater distribution of scores compared to the SOFA 0 to 4 range. Unless an individual has a known nonsurvivable injury or illness, they would be considered for definitive care. The SOFA score is not relied upon to predict mortality, but it is considered in ranking a "sicker," high- scoring patient. If adequate critical care resources are available, then patients would receive care; in other words, business as usual. When a resource is limited, the patient who is most likely to benefit from that resource would receive that limited resource first.

The editorial by Rubinson et $\mathrm{al}^{2}$ warns that the use of SOFA in isolation to determine resource allocation during a disaster could be "catastrophic." We intend to replace SOFA with MSOFA in calculating a patient's MCCRAS score and invite the disaster medicine community to evaluate the Wisconsin approach critically as an effective disaster patient care triage tool.

$$
\begin{array}{r}
\text { Ronald G. Pirrallo, MD, MHSA } \\
\text { Gloria Murawsky Akuna, RN, NREMTP } \\
\text { Dennis J. Tomczyk } \\
\text { Medical College of Wisconsin }
\end{array}
$$

\section{REFERENCES}

1. Grissom CK, Brown SM, Kuttler KG, et al. A modified sequential organ failure assessment score for critical care triage. Disaster Med Public Health Prep. 2010;4(4):277-284.

2. Rubinson L, Knebel A, Hick JL. MSOFA: An important step forward, but are we spending too much time on the SOFA? Disaster Med Public Health Prep. 2010;4(4):270-272.

3. Wisconsin Hospital Association. Disaster preparedness: allocation of scarce resources. http://www.wha.org/disasterPreparedness/ScarceResources .aspx. Accessed January 7, 2011.

4. Pirrallo RG, Akuna GM. Hospital resource and clinical management guidelines for hospital healthcare providers when routine critical care resources are not available. Medical College of Wisconsin Center for Medical Incident Management and Preparedness. www.mcw.edu/emergencymed/MIMAP /MCCRAS.htm. Accessed January 7, 2011.

5. White DB, Katz MH, Luce JM, Lo B. Who should receive life support during a public health emergency? Using ethical principles to improve allocation decisions. Ann Intern Med. 2009;150(2):132-138.

\title{
Correction
}

Errors in Author Byline and Author Affiliations. In the article titled "Radiological Incident Preparedness: Planning at the Local Level," by C. M. Tan, D. J. Barnett, A. J. Stolz, and J. M. Links, published in the March 2011 Supplement issue of Disaster Medicine and Public Health Preparedness (2011;5:S151-S158), author Adam J. Stolz was incorrectly listed as having an MPH degree. In addition, Mr Stolz was incorrectly listed as being affiliated with Bloomberg School of Public Health, Johns Hopkins University. Mr Stolz is affiliated with the City of Baltimore, Mayor's Office of Emergency Management. The article was corrected online. 